\title{
Lasing in a cholesteric liquid crystal doped with derivative of triphenylamine and 1,8-naphthalimide, and optical characterization of the materials
}

${ }^{1}$ Dudok T. H., ${ }^{1}$ Krupych O. M., ${ }^{1}$ Savaryn V. I., ${ }^{2}$ Cherpak V. V.,

${ }^{2}$ Fechan A. V., ${ }^{3}$ Gudeika D., ${ }^{3}$ Grazulevicius J. V., ${ }^{4}$ Pansu B. and

${ }^{1,4}$ Nastishin Yu. A.

${ }^{1}$ Vlokh Institute of Physical Optics, 23 Dragomanov Street, 79005 Lviv, Ukraine

${ }^{2}$ Lviv Polytechnic National University, 12 Bandery Street, 79013 Lviv, Ukraine

${ }^{3}$ Department of Organic Technology, Kaunas University of Technology, Radvilenu pl. 19, LT-50254 Kaunas, Lithuania

${ }^{4}$ Laboratoire de Physique des Solides, UMR 8502, Universite Paris-Sud, 91405 Orsay, France

Received: 21.07 .2014

\begin{abstract}
Recently derivatives of triphenylamine and 1,8-naphthalimide have been designed and synthesized as materials for organic light emitting diodes and solar cells. We have doped a cholesteric liquid crystal (ChLC) with $1 \mathrm{wt}$. \% of one of the compounds of this series, a day 4-((E)-2-( $N$-(2-ethylhexyl)-1,8- naphthalimid- 4-yl) vinyl) phenyl) benzenamine (or DG56) and performed optical characterization of the mixture as a material for laser generation. We have obtained such characteristics as light absorption, photoexcitation and fluorescent emission spectra, scalar orientational order parameter $S$, dispersion dependences of the birefringence, absorption indices, and dichroism for the dye molecules dissolved in the ChLC matrix. A large enough value of $S=0.55$ measured for the dye molecules in the ChLC matrix indicates that the molecular planes of the dye are oriented roughly parallel to the nematic molecules. A laser emission from the dye-doped cholesteric with planar orientation showing Grandjean texture is observed at the long-wavelength edge of the cholesteric photon bandgap (PhBG). This confirms a PhBG nature of the laser line and evidences additionally that the dye molecular planes are parallel to the LC molecules. We have also found that the dye-doped ChLC under study represents a promising material for laser generation in $\mathrm{ChLC}$ matrices.
\end{abstract}

Keywords: mirrorless lasing, mirrorless laser, photonic band-gap edge lasing, dye-doped cholesteric liquid crystals, liquid crystal laser

PACS: $42.55 . \mathrm{Mv}, 42.55 . \mathrm{Sa}, 42.55 . \mathrm{Tv}, 42.70 . \mathrm{Qs}, 61.30 .-\mathrm{v}$, 77.84.Nh, 78.60.Lc UDC: $538.958+535.343 .32+681.7 .069 .2+52-626$

\section{Introduction}

During the last twenty years there has been considerable progress in the development of compact, inexpensive and simple in fabrication mirrorless all-organic lasers with wavelength tunability and low optical pumping-energy thresholds. Though the lasing effect in dye-doped cholesteric liquid crystals (ChLCs) has been discovered [1-3] about forty years ago, it has received considerable interest only in the recent two decades, after announcement of the concept of photonic crystals (PCs) [4-6]. It has been unambiguously shown that, due to so-called selective light reflection, a ChLC is a 1D PC capable for photonic bandgap (PhBG) lasing [7].

A ChLC is a chiral nematic in which the director $\vec{n}$ describing preferential orientation of long molecular axes spontaneously rotates in a helical way around an axis perpendicular to $\vec{n}$. The length 
(measured along the helical axis), at which the director rotates by $2 \pi$ is called a cholesteric pitch $P$. Due to periodicity of director orientation, the ChLCs are PhBG materials, whenever the pitch remains comparable to the light wavelength. The latter implies that light of the wavelengths $\lambda \sim P$ with the circular polarization of the same handedness as that of the ChLC is totally reflected by the cholesteric structure, thus being totally prohibited for transmission, whereas the light of the same $\lambda$ but of the opposite handedness of circular polarization is not affected by the cholesteric structure and is totally transmitted. The $\mathrm{PhBG}$ is spectrally centred at the wavelength $\lambda_{c}=P \bar{n}$ (with $\bar{n}=\left(n_{e}+n_{o}\right) / 2$ being the refractive index, which is an average of the refraction indices $n_{e}$ and $n_{o}$ for the extraordinary and ordinary light waves of the corresponding non-twisted nematic). It has the spectral width $\Delta \lambda=P \Delta n$, where $\Delta n=n_{\|}-n_{\perp}$ is the linear birefringence of the corresponding non-twisted nematic LC (here $n_{\|}=n_{e}$ and $n_{\perp}=n_{o}$ are the refractive indices for linearly polarized light waves respectively parallel and perpendicular to the nematic director $\vec{n}$ ).

Nevertheless, ChLCs are not trivial mirrors: they are media in which one of the eigenwaves suffers multiple internal reflection during its propagation, forming a standing wave with strongly preferred backward leakage. As a result, such a cholesteric structure represents a natural resonator with a distributed feedback for properly circularly-polarized light of the wavelengths $n_{\perp} P<\lambda<n_{\|} P$. Entering the cholesteric structure, a light wave splits into two eigenwaves of the opposite handedness with the circular (more generally, elliptical) polarizations, one of which suffering the selective reflection and the other freely propagating through a LC sample. Then, after doping such a cholesteric with a dye revealing fluorescent emission band (FEB) overlapping with the cholesteric $\mathrm{PhBG}$, one obtains a natural mirrorless laser, provided that pumping is performed with the wavelength falling into the absorption band of the dye. The efficiency of dye-doped ChLC lasers is governed, on the one hand, by the emission characteristics of the dye and, on the other hand, it requires proper selection of the ChLC matrix.

Selection of the dyes with desired absorption and emission properties is crucial for providing the best efficiency of the dye lasers. Recently a series of novel dyes, derivatives of triphenylamine and 1,8-naphthalimide have been designed and synthesized as working materials for the organic light emitting diodes [8]. These dyes manifest the fluorescence with high quantum yield. For the dye studied in this work (a compound labelled by ' 8 ' in Ref. [8]) it is equal to about 0.64 . In its turn, proper selection of the ChLC matrix implies at least the following: (1) the fact of overlapping of the cholesteric PhBG with the FEB of the dye, and (2) the degree of the orientational order of the dye molecules in the ChLC matrix should be as high as possible, i.e. the scalar orientational order parameter for the dye molecules in the ChLC matrix should preferably be comparable to that for the LC molecules.

The purpose of the present study is threefold: (1) to collect information on the light absorption, emission and excitation spectra of the dye 4-((E)-2-(N-(2-ethylhexyl)-1,8-naphthalimid- 4-yl)vinyl) phenyl)benzenamine (abbreviated further on as DG56) in the LC matrix, (2) to examine whether this dye is suitable for the laser generation in this matrix, and (3) to measure the scalar orientational order parameter of the dye molecules in the above matrix.

\section{Experimental: materials and setup}

The chemical procedures of synthesis of the dye under test and its characterization may be found in Ref. [8]. We have chosen a commercially available short-pitch cholesteric mixture KET90700 (from Jiangsu Hecheng Chemical Materials Co., Ltd., HCCH) as a basic cholesteric compound for 
preparation of dye-doped cholesteric samples for lasing. A wide (from the room temperatures up to $80^{\circ} \mathrm{C}$ ) temperature range and a relatively weak temperature dependence of location of the $\mathrm{PhBG}$ (from $550 \mathrm{~nm}$ at the room temperatures to $650 \mathrm{~nm}$ at $80^{\circ} \mathrm{C}$ ) are strong advantages of this material.

To find the position of the PhBG, we measured the reflection spectra of this mixture filled in a cell with Grandjean texture, for which the LC molecules are parallel (and the helical axis is perpendicular) to the cell substrates everywhere except for the regions of defects called as 'oily streaks'. The quality of LC alignment was examined under a polarizing microscope. Notice that short-pitch cholesterics are hard to align. Even using a rubbed polymer film as an alignment layer spin-coated on the substrates, which usually provides quite high quality of nematic alignment, cannot ensure obtaining the same alignment quality for the short-pitch cholesterics based on the same nematic doped with a twisting agent. Commonly the microscopy displays a presence of 'oily streaks' forming a network, such that the regions with planar molecular alignment appear as 'windows' of irregular shapes framed by the 'oily streaks'. Such a pattern observed under optical microscope is called a Grandjean texture. The mean size of the 'windows' with planar alignment in typical Grandjean textures ranges from microns in case of poor alignment to hundreds of microns for relatively good alignment. The quality of the alignment appears to be different from cell to cell, varying along the cells and showing a tendency to slight spontaneous improvement with time due to annihilation of defects. Since PhBG laser lines appear at one (or both) of the PhBG edges, their spectral positions are usually hardly affected by the quality of the alignment, as long as a LC sample has a typical Grandjean texture. Finally, the quality of the planar alignment can be improved by forcing the ChLC to flow via pressing (or shifting) one of the substrates.

To check whether the dye DG56 is suitable for lasing in a cholesteric matrix, we dissolved it in the amount of $1 \mathrm{wt} . \%$ in the cholesteric material KET 90700 mixed with $15 \mathrm{wt} . \%$ of nematic E7 (from Merk), which was added to KET 90700 in order to overlap the cholesteric PhBG with the FEB of the dye. The dye-doped cholesteric cell was optically pumped by laser radiation with the wavelength of $\lambda=532 \mathrm{~nm}$, which was obtained as a second harmonic induced by a pulse solid-state laser light ( $\lambda=1064 \mathrm{~nm}$, the pulse duration $\tau=6 \mathrm{~ns}$, the repetition period $T=1 \mathrm{~s}$, and the energy per pulse $15 \mathrm{~mJ}$ ) in such materials as borate crystals or glasses [9]. The pumping light was focused on the dye-doped ChLC cell with the Grandjean texture. The holder of the ChLC cell was mounted on a rotation stage, allowing one for high-precision ( the angular accuracy better than $0.5^{\circ}$ ) variations of the cell orientation with respect to the axis of the pumping light beam. Detection system was based on a miniature fibre-optic spectrometer S2000 (Ocean Optics) mounted to rotate around the rotation stage axis. A sketch of our experimental setup for studying the laser generation and its spectral detection is shown in Fig. 1.

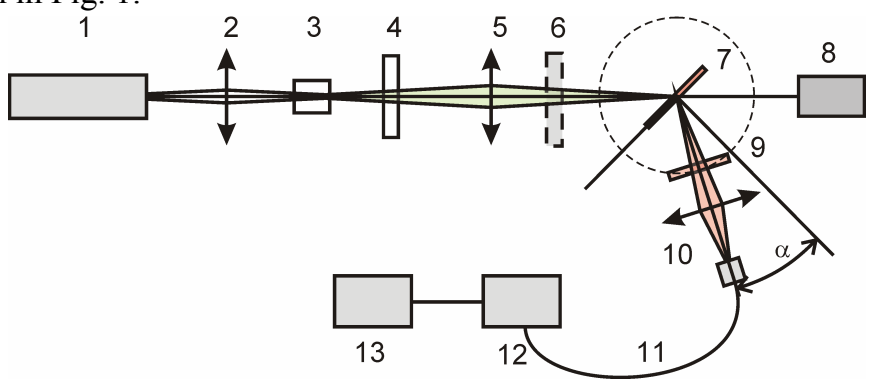

Fig. 1. Scheme of experimental setup for studying laser generation by our dye-doped ChLC and detecting its spectral characteristics: 1 - pulse solid-state laser $(\lambda=1064 \mathrm{~nm}), 2$ - focusing lens (focal length $f=0.15 \mathrm{~m}$ ), 3 - material for second harmonic generation, 4 - optical filter (transmission not lower than $95 \%$ at $\lambda=532 \mathrm{~nm}$ and not higher than $3 \%$ at $\lambda=1064 \mathrm{~nm}$ ), 5 - focusing lens (focal length $f=0.2 \mathrm{~m}$ ), 6 - grey filter, 7 -dye-doped ChLC cell, 8 - optical powermeter, 9 - optical filter (transmission at $\lambda=532 \mathrm{~nm}$ not higher than $1 \%$ ), $10-$ focusing lens (focal length $f=0.015 \mathrm{~m}$ ), 11 - fibre cable, 12 - fibre-optic microspectrometer, and 13 - computer. 
Optical characterization of the dye performed by us has included measuring the absorption, photoexcitation and the emission spectra of the dye in the LC matrix and determining scalar orientational order parameter $S$ that characterizes degree of orientational order of the dye molecules in the LC matrix. To do that, we have dissolved the dye in the nematic material E7. We remind that E7 is a material which we have added to the basic cholesteric mixture KET90700 for controlling the PhBG location. Finally, we remark that, because of a twisted structure of the cholesteric, the optical characterization cannot be performed for the dye dissolved directly in the lasing mixture KET $90700+$ E7.

\section{Optical characterization}

\subsection{Absorption, emission and excitation spectra}

Curve 1 in Fig. 2 corresponds to the optical absorption spectrum of the dye dissolved in the nematic E7 (the weight concentration 1\%). It shows a fundamental absorption edge below $400 \mathrm{~nm}$ and a wide absorption band located roughly between 400 and $550 \mathrm{~nm}$.

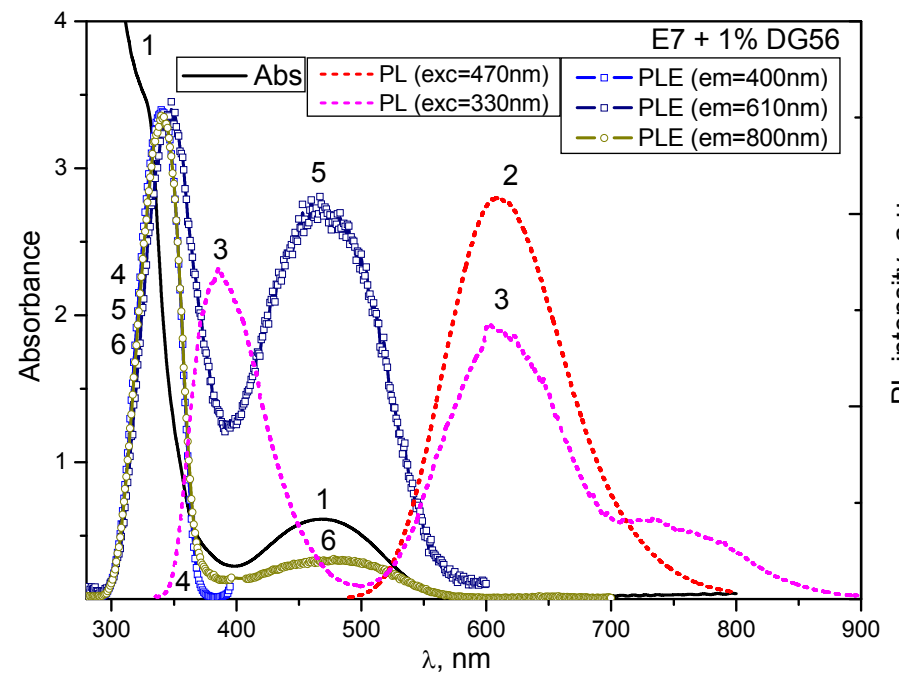

Fig. 2. (Colour online) Spectra of optical absorption (black curve, 1), photoluminescence excited at $\lambda=470$ (red curve, 2) and $\lambda=330 \mathrm{~nm}$ (pink curve, 3 ), and photoexcitation of the emission bands with the maxima located at $\underline{\lambda}=390 \mathrm{~nm}$ (blue curve, 4), $\lambda=610$ (navy curve, 5) and $\lambda=750 \mathrm{~nm}$ (dark yellow curve, 6 ).

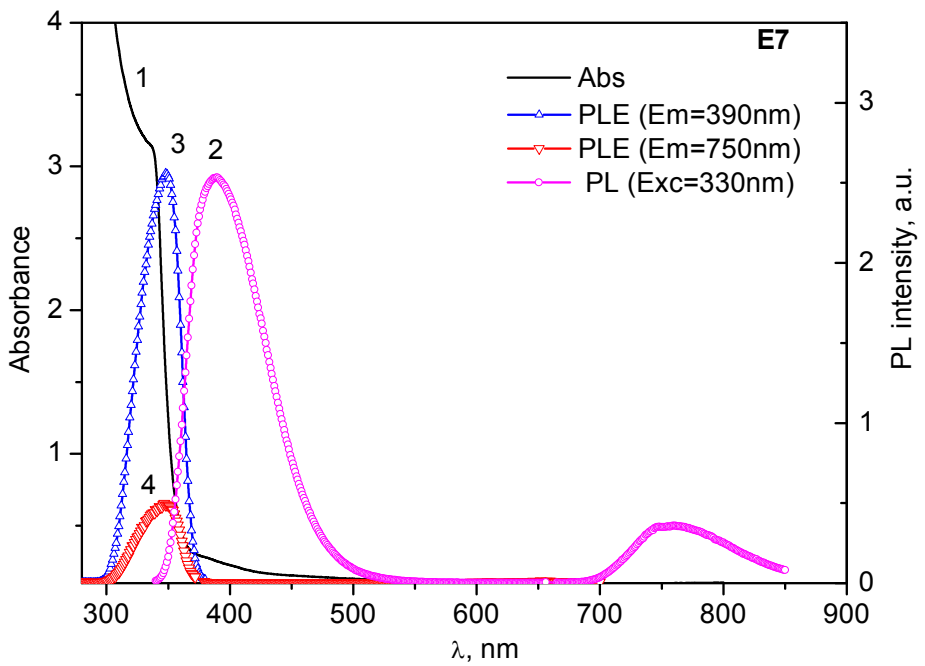

Fig. 3. (Colour online) Spectra of optical absorption (black curve, 1), photoluminescence excited at $\lambda=330 \mathrm{~nm}$ (pink curve, 2), and photoexcitation of the emission bands with the maxima located at $\lambda=390 \mathrm{~nm}$ (blue curve, 3) and $\lambda=750 \mathrm{~nm}$ (red curve, 4).

Of course, the most efficient optical pumping can be expected at the wavelength of maximum absorption $(\lambda=470 \mathrm{~nm})$. Nonetheless, Fig. 3 suggests that the optical pumping can still be performed using a readily available green laser line $\lambda=532 \mathrm{~nm}$, which falls into the absorption band of 
the dye. Photoexcitation at $\lambda=470 \mathrm{~nm}$ reveals an emission band in the spectral region of 500-700 nm, with the maximum located at $\lambda=610 \mathrm{~nm}$ (see curve 2 in Fig. 2). Excitation at $\lambda=330 \mathrm{~nm}$ results in three emission bands (see pink curve 3 in Fig. 2), with their maxima peaked at 390,610 and $750 \mathrm{~nm}$. The excitation spectra for the three latter emission bands correspond respectively to the curves 4, 5 and 6 in Fig. 2.

The band centred at $610 \mathrm{~nm}$ can be unambiguously assigned to the dye emission. To understand the origin of the other two bands located at 390 and $750 \mathrm{~nm}$, we have measured the appropriate spectra of absorption (curve 1 in Fig. 3), photoemission with the excitation at $\lambda=330 \mathrm{~nm}$ (curve 2) and excitation spectra for the emission bands with their maxima at 390 (curve 3 ) and $750 \mathrm{~nm}$ (curve 4) for the pure material E7 without dye and found that these emission bands, namely at 390 and $750 \mathrm{~nm}$ are due to the emission from the nematic E7 molecules.

\subsection{Scalar orientational order parameter}

To characterize the degree of orientational order $S$ of the dye molecules placed in the LC matrix, we have employed a technique described earlier in Ref. [10]. The $S$ parameter has been determined basing on the experimental transmission spectra $T_{\|}(\lambda)$ and $T_{\perp}(\lambda)$ (see Fig. 4). These have been studied for a planarly aligned nematic cell filled with the nematic E7 doped with 1 wt.\% of the dye under test. The cell has been placed in between parallel polarizers and the measurements have been conducted under conditions that the nematic director is oriented parallel and perpendicular to the transmission direction of the polarizers. Issuing from the $T_{\|}(\lambda)$ and $T_{\perp}(\lambda)$ data displayed in Fig. 4, we have calculated the averaged value $S=0.55$ (see Fig. 5). Here we have used the data for the dispersions of refractive indices $n_{\|}(\lambda)$ and $n_{\perp}(\lambda)$ reported in Refs. [11,12] for the light polarizations parallel and perpendicular to the nematic director, which yield in the dispersion formulae $n_{\|}=1.6933+0.0078 \lambda^{-2}+0.0028 \lambda^{-4}$ and $n_{\perp}=1.4990+0.0072 \lambda^{-2}+0.0003 \lambda^{-4}$.

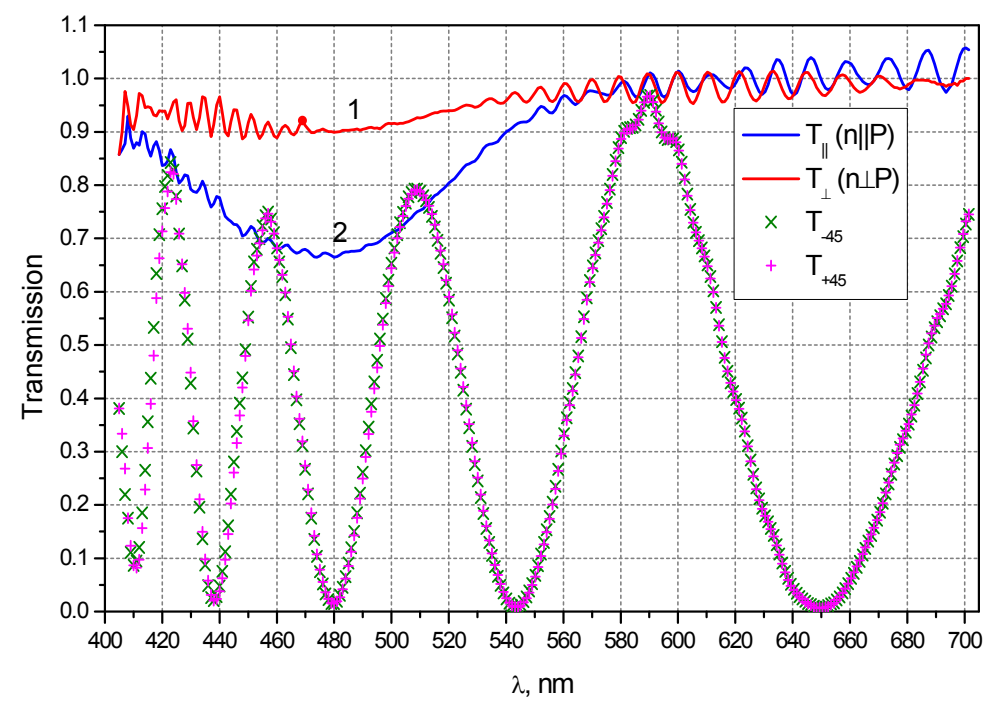

Fig. 4. (Colour online) Optical transmission spectra $T_{\|}(\lambda)$ (red curve, 1$), T_{\perp}(\lambda)$ (blue curve, 2) and $T_{45}(\lambda)$ (pink crosses) measured for linearly polarized light incident on a flat cell filled with the nematic E7 doped with $1 \mathrm{wt} . \%$ of the dye DG56 (planar director orientation at the bounding substrates), which is placed in between parallel polarizers. The three curves correspond to parallel, perpendicular and diagonal orientations of the nematic director with respect to the light polarization direction set by the polarizer. Complementary data for the angle of $-45^{\circ}$ (green crosses) are obtained to check the measuring accuracy. 


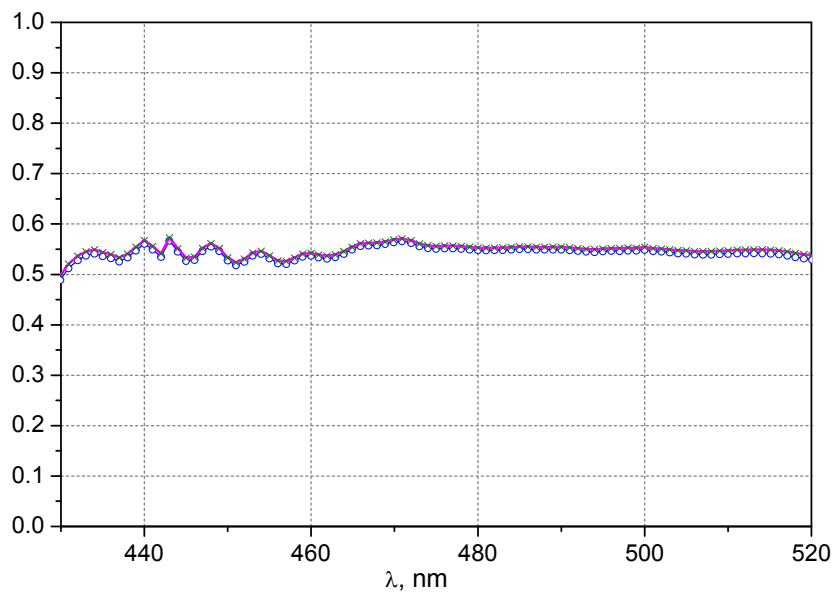

Fig. 5 (Colour online) Scalar orientational order parameter for the molecules of the DG56 dye dissolved in the nematic $E 7$, as calculated from the experimental data $T_{\|}(\lambda)$ and $T_{\perp}(\lambda)$ displayed in Fig. 4.

Accounting for that the molecules of the DG56 dye are not mesogenic, the value $S=0.55$ obtained by us seems to be rather high. It is comparable to the values $S=0.6$ typical for a thermotropic nematic far from its clearing point. This indicates that the dye molecular planes are oriented roughly parallel to the nematic molecules. Below we will further confirm the latter by the fact that the relevant lasing line is observed at the long-wavelength edge of the cholesteric PhBG.

As expected, the $S$ parameter does not depend on $\lambda$, which evidences for reliability of our technique used for determining $S$. Slight oscillations seen in the $S(\lambda)$ dependence (Fig. 5) are only artefacts appearing, most probably, due to multiple light reflection interference that occurs at the bounding cell substrates.

\subsection{Dispersion of optical birefringence and absorption indices}

We have additionally measured the transmission spectrum $T_{45}(\lambda)$ for the case when the nematic director is oriented at the azimuthal angle of $45^{\circ}$ with respect to the light polarization direction set by the polarizer (see pink crosses in Fig. 4). The similar data have been obtained for the angle of $-45^{\circ}$ (green crosses). They serve as a self-checking test revealing high reliability of our transmission measurements. Using the data of Fig. 4 and the relationship suggested in Ref. [10],

$$
\cos \Gamma=\frac{4 T_{45}-\left(T_{\|}+T_{\perp}\right)}{2 \sqrt{T_{\|} T_{\perp}}},
$$

we have calculated dispersion of the phase retardation $\Gamma(\lambda)$ appearing between the ordinary and extraordinary waves that propagate through the nematic. By definition, we have $\Gamma=2 \pi \Delta n d / \lambda$ and so the dependence $\Delta n(\lambda)$ van easily be calculated following from the $\Gamma(\lambda)$ data (see Fig. 6). Some discontinuities observed in the $\Delta n(\lambda)$ dependence in Fig. 6 are artefacts of calculations of the inverse function $\mathrm{Cos}^{-1}$ (also known as arccos). Here the solid curve represents smoothing of the experimental data.

Since the thickness $(d=11 \mu \mathrm{m})$ of the nematic layer is known in advance, the $T_{\|}(\lambda)$ and $T_{\perp}(\lambda)$ data yield also the dispersion dependences of the absorption indices $\kappa_{\|}(\lambda)$ (curve 1 in Fig. 7) and $\kappa_{\perp}(\lambda)$ (curve 2) for the light polarizations respectively parallel and perpendicular to the director, as well as their difference $\Delta \kappa(\lambda)=\kappa_{\|}(\lambda)-\kappa_{\perp}(\lambda)$ (curve 3). All of these dependences 
have been obtained using FFT smoothing of the experimental data. Again, the oscillations on the experimental dependences are due to the multiple light reflection interference.

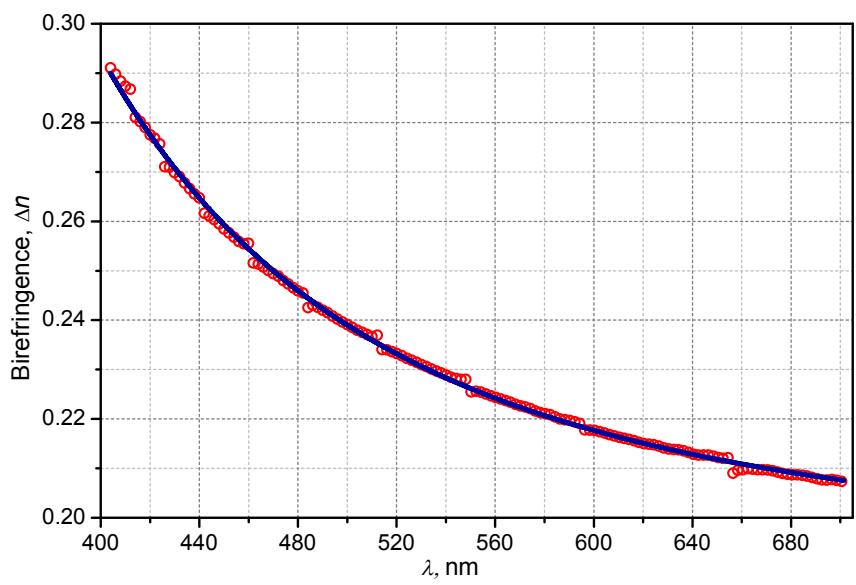

Fig. 6. (Colour online) Dispersion of optical birefringence for the nematic E7 doped with $1 \%$ of DG56.

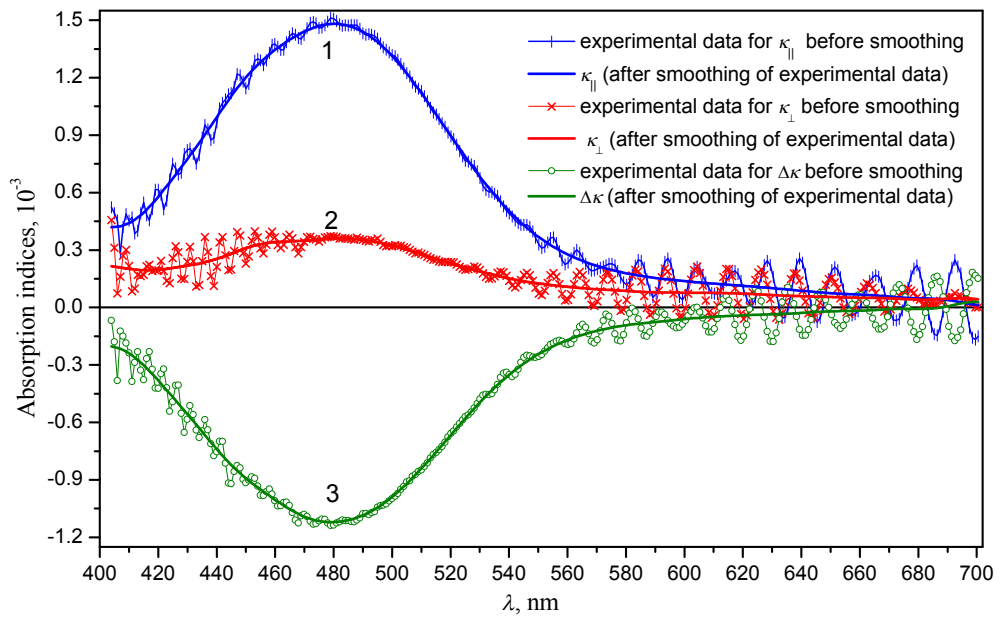

Fig. 7. (Colour online) Dispersion dependences of the absorption indices $\kappa_{\|}(\lambda)$ (blue curve, 1$)$ and $\kappa_{\perp}(\lambda)$ (red curve, 2), and their difference $\Delta \kappa(\lambda)=\kappa_{\|}(\lambda)-\kappa_{\perp}(\lambda)$ (green curve, 3) for the nematic E7 doped with $1 \%$ of DG-56, as obtained via smoothing the corresponding experimental data displayed by hyphens, crosses and circles.

Hence, the transmission spectra $T_{\|}(\lambda), T_{\perp}(\lambda)$ and $T_{45}(\lambda)$ have enabled us to characterize optically both the LC material and the dye used for the laser generation. As a result, we have obtained the scalar orientational order parameter for the dye molecules dissolved in the LC matrix, and the dispersion dependences of optical birefringence, absorption indices and dichroism. These results may be further used to estimate location of the cholesteric PhBG for the cholesteric mixtures under study. Namely, if the cholesteric pitch $P$ is known, then the short- and long-wavelength edges of the cholesteric PhBG can be calculated respectively as $\lambda_{\perp}=P n_{\perp}$ and $\lambda_{\|}=P n_{\|}$. Here the cholesteric pitch can be estimated basing on a so-called helical twisting power $\beta$ of the twisting dopant as $P=(c \beta)^{-1}$, where $c$ is the concentration of the chiral dopant. Thus, having the $\lambda_{\perp}$ and $\lambda_{\|}$values determined experimentally for a given concentration $c$ of the chiral agent, one can calculate the 
position of the $\mathrm{PhBG}$ for any concentrations. We will use such a procedure for predicting the concentration of the chiral dopant at which the cholesteric PhBG overlaps with the FEB of the dye.

We have found for the chiral agent CB15 (from Merk) with $\beta=+7.3 \mu \mathrm{m}^{-1}$ placed in E7 that the cholesteric PhBG and the dye FEB should overlap at $c=38$ wt. \% . Fig. 8 shows the optical transmission spectra for the mixtures $\mathrm{E} 7+38 \% \mathrm{CB} 15$ and $\mathrm{E} 7+38 \% \mathrm{CB} 15+1 \% \mathrm{DG} 56$. The cholesteric $\mathrm{PhBG}$ for these mixtures (see red curve 2 in Fig. 8) indeed overlaps with the dye FEB (see black curve 3 in Fig. 8). The cholesteric PhBG is easily recognized in the transmission spectra in Fig. 8 as a flat 'cavity' in the region $600-650 \mathrm{~nm}$. The edges of this 'spectral cavity' are those of the cholesteric PhBG. A slight shift of the PhBG for the dye-doped mixture when compared with that of the dye-free mixture agrees with expected unwinding action of the dye molecules, since they are not chiral.

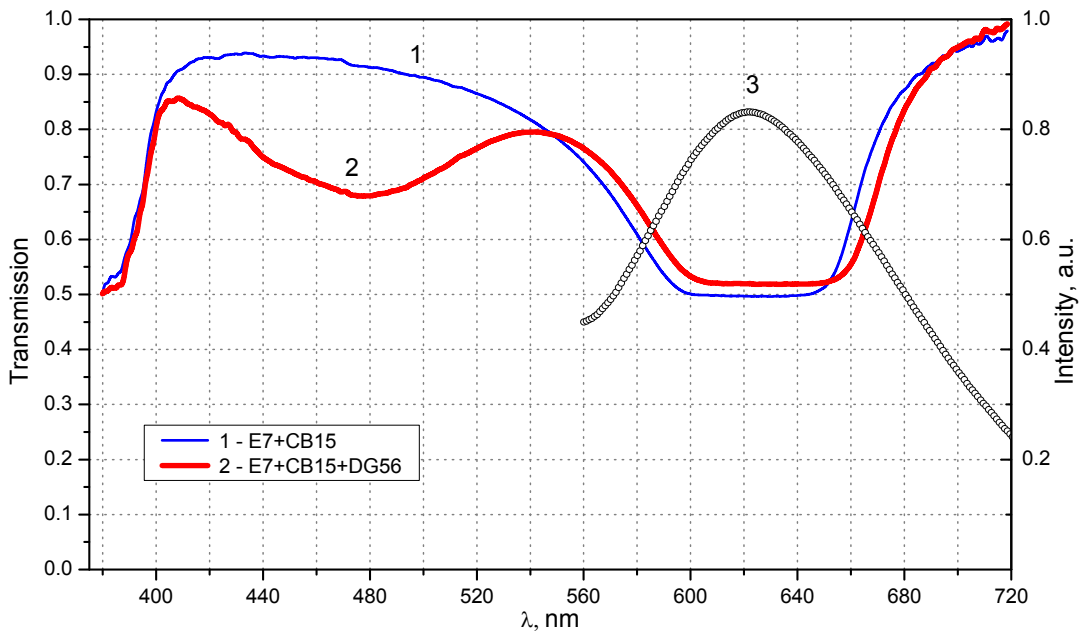

Fig. 8. (Colour online) Optical transmission spectra for the dye-free (blue curve, 1) and dye-doped (red curve, 2) cholesteric mixtures $\mathrm{E} 7+38 \% \mathrm{CB} 15$ and $\mathrm{E} 7+38 \% \mathrm{CB} 15+1 \% \mathrm{DG} 56$, which are normalized with respect to the spectrum of the same cell filled with the pure E7. Black curve 3 corresponds to fluorescence spectrum of the dye DG56 placed in E7.

It is worth checking whether the dye-doped mixture $\mathrm{E} 7+38 \% \mathrm{CB} 15+1 \% \mathrm{DG} 56$ can be used for laser generation under suitable optical pumping. However, it has turned out that the temperature (the clearing point), at which the cholesteric transforms into the isotropic phase for this mixture, is only few Celsius degrees above the room temperature, which makes it too unstable with respect to the temperature changes. Lowering of the clearing point from $60^{\circ} \mathrm{C}$ typical for the pure $\mathrm{E} 7$ to the region of the room temperature, when the chiral dopant $\mathrm{CB} 15$ is added, is because the ChLC phase in the $\mathrm{CB} 15$ material exists only below $-40^{\circ} \mathrm{C}$. For this reason, instead of the $\mathrm{CB} 15$-bassed material, we have made use of the cholesteric mixture KET90700+15\%E7+1\%DG56 in order to test the dye DG56 for lasing in the ChLC. Notice that in our case the cholesteric material KET90700 may be considered as a twisting agent for the nematic E7.

\section{Lasing of DG56 dye placed in ChLC}

Fig. 9 shows the optical transmission spectrum for the mixture KET90700+15\%E7+1\%DG56 superimposed with its emission spectrum obtained when a flat cell of this mixture with the Grandjean texture is pumped with the pulse laser light of $\lambda=532 \mathrm{~nm}$ (the other parameters of light radiation are the same as given in Section 2). As seen from Fig. 9, the spectral band of spontaneous 
emission, which is the FEB of the dye (seen in Fig. 9 as a wide 'bump' in the region of 600-700 nm) overlaps with the cholesteric PhBG. A sharp peak located at $\lambda=625 \mathrm{~nm}$ is a lasing line. It is evident that this laser line coincides with the long-wavelength edge of the cholesteric PhBG. The latter confirms a PhBG nature of the line observed at $\lambda=625 \mathrm{~nm}$ and suggests that the dye molecular planes are roughly parallel to the LC molecules. The above statement agrees well with the conclusion drawn in this work from the fact that the orientational order value $S$ of the dye molecules is comparable to the values typical for thermotropic nematics.

It is worth reminding that, according to Ref. [13], lasing in a dye-doped ChLC can be observed at the both PhBG edges. However, these two PhBG modes can have different pumping thresholds. If the transition dipole moment $\vec{d}$ of the dye molecules, which is usually parallel to the molecular planes, is locally parallel to the ChLC molecules (i.e., to the local nematic director, $\vec{d} \| \vec{n}$ ), then the laser line located at the long-wavelength edge $\lambda_{\|}$of the cholesteric PhBG has lower threshold. On the contrary, the laser line located at the short-wavelength $\mathrm{PhBG}$ edge $\lambda_{\perp}$ would have lower threshold if we have the condition $\vec{d} \perp \vec{n}$. Different dyes can have different orientations of their $\vec{d}$ vectors with respect to the direction $\vec{n}$. Moreover, one should expect that the scalar orientational order $S \rightarrow-1 / 2$ in case of $\vec{d} \perp \vec{n}$.

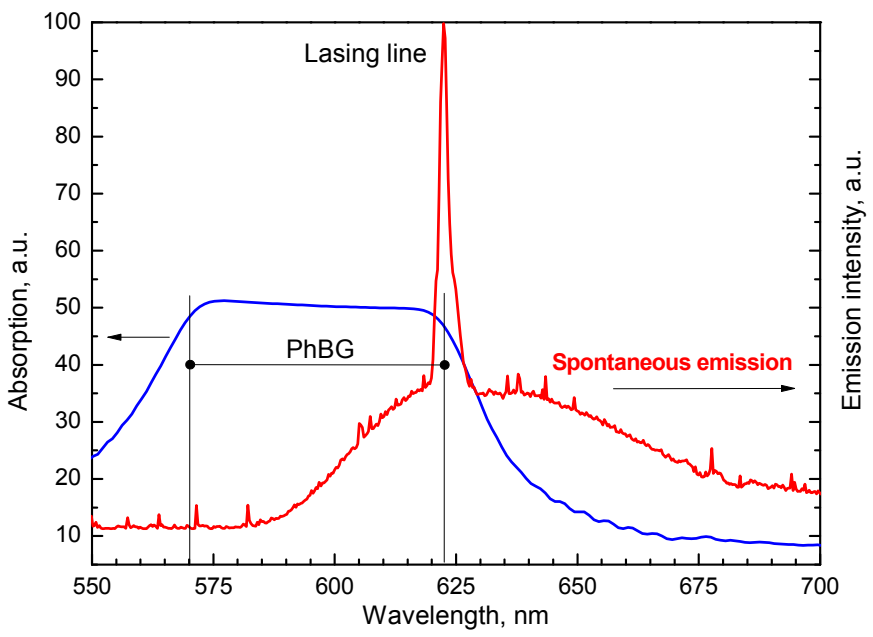

Fig. 9. (Colour online) Emission spectrum (red curve and right abscissa axis) of the cholesteric mixture KET90700+E7 (15 wt.\%) doped with the dye DG-56 (1 wt.\%), as obtained due to optical pumping at $\lambda=532 \mathrm{~nm}$.

Thin vertical lines correspond to the edges $\lambda_{\perp}$ and $\lambda_{\|}$of the cholesteric PhBG observed in the transmission spectrum (see blue curve and left abscissa axis). Composition of the cholesteric mixture is chosen such that to match the long-wavelength PhBG edge with the maximum of dye fluorescence emission band. Notice that lasing line coincides with the long-wavelength edge $\lambda_{\|}$of the PhBG.

\section{Conclusion}

We have performed optical characterization of a ChLC material and a dye DG56 used for laser generation. The following material parameters have been obtained: the light absorption, the photoexcitation and emission spectra, the scalar orientational order parameter $S$, and the dispersion dependences of the optical birefringence, absorption indices and the dichroism for the dye molecules dissolved in the LC matrix. Rather high value of the scalar orientational order parameter ( $S=0.55$ ) obtained for dye molecules in our ChLC matrix indicates that the transition dipole 
moment of the dye molecules (which is usually parallel to molecular planes of the dye) is preferentially parallel to the nematic molecules. A laser emission from the dye-doped cholesteric with the planar orientation showing the Grandjean texture is observed at the long-wavelength side of the cholesteric PhBG. This confirms the PhBG nature of the laser line and serves as additional evidence that the dye molecular planes are parallel to the LC molecules. Our experimental results suggest that the dye-doped $\mathrm{ChLC}$ material under study may represent a promising material for the laser generation in ChLC matrices.

\section{References}

1. Goldberg L S and Shnur J M, 1973. Tunable internal-feedback liquid. U. S. Patent No $3,771,065$.

2. Kukhtarev N V, 1978. Cholesteric liquid crystal laser with distributed feedback. Sov. J. Quant. Electron. 8: 774-776.

3. Il'chishin I P, Tikhonov E A, Tishchenko V G and Shpak T M, 1981. Generation of tunable radiation by impurity cholesteric liquid crystals. JETP Lett. 32: 24-27.

4. Yablonovitch E, 1987. Inhibited spontaneous emission in solid-state physics and electronics. Phys. Rev. Lett. 58: 2059-2062.

5. Yablonovitch E, 2001. Photonic crystals: Semiconductors of light. Sci. American. December: $47-55$.

6. John S, 1984. Electromagnetic absorption in a disordered medium near a photon mobility edge. Phys. Rev. Lett. 53: 2169-2172.

7. Kopp V I, Fan B, Vithana H K M and Genack A Z., 1998. Low-threshold lasing at the edge of a photonic stop band in cholesteric liquid crystals. Opt. Lett. 23: 1707-1709.

8. Gudeika D, Michaleviciute A, Grazulevicius J V, Lygaitis R, Grigalevicius S, Jankauskas V, Miasojedovas A, Jursenas S and Sini G, 2012. Structure properties relationship of donor -acceptor derivatives of triphenylamine and 1,8-naphthalimide. J. Phys. Chem. C. 116: 14811-14819.

9. Padlyak B V, Adamiv V T, Burak Ya V and Kolcun M, 2013. Optical harmonic transformations in borate glasses with $\mathrm{Li}_{2} \mathrm{~B}_{4} \mathrm{O}_{7}, \mathrm{LiKB}_{4} \mathrm{O}_{7}, \mathrm{CaB}_{4} \mathrm{O} 7$, and $\mathrm{LiCaBO}_{3}$ compositions. Physica $\mathrm{B}$. 412: 79-82.

10. Nastishin Yu A, Liu H, Schneider T, Nazarenko V, Vasyuta R, Shiyanovskii S V and Lavrentovich O D, 2005. Optical characterization of the nematic lyotropic chromonic liquid crystals: Light absorption, birefringence, and scalar order parameter. Phys. Rev. E. 72: 041711.

11. http://refractiveindex.info/?shelf $=$ other\&book=E7\&page $=$ Li-e

12. http://refractiveindex.info/?shelf $=$ other\&book=E7\&page $=$ Li-o

13. Schmidtke J and Stille W, 2003. Fluorescence of a dye-doped cholesteric liquid crystal film in the region of the stop band: theory and experiment. Eur. Phys. J. B. 31: 179-194.

Dudok T. H., Krupych O. M., Savaryn V. I., Cherpak V. V., Fechan A.V., Gudeika D., Grazulevicius J. V., Pansu B. and Nastishin Yu. A. 2014. Lasing in a cholesteric liquid crystal doped with derivative of triphenylamine and 1,8-naphthalimide, and optical characterization characterization of the materials. Ukr.J.Phys.Opt. 15: $162-172$.

Анотація. Нещуодавно було розроблено та синтезовано похідні тріфеніламіну і 1,8-нафталіміду як матеріали для органічних світлодіодів і сонячних батарей. Ми легували холестеричні рідкі кристали (ХРК) однією зі сполук иієї серії - барвником 4-((E)-2-(N-(етилгексил)1,8-нафталімід-4-іл)вініл)феніл)бензенамін (DG56). Вміст барвника становив 1 мас. \%. Було

Ukr. J. Phys. Opt. 2014, Volume 15, Issue 3 
Dudok T. H. et al

здійснено оптичну характеризацію ичієї суміші як матеріалу для лазерної генерації. Одержано такі характеристики иьього матеріалу як поглинання світла, спектри збудження та флуоресиентного випромінювання, скалярний параметр орієнтаиійного порядку $S$, дисперсійні залежності двопроменезаломлення, а також коефіиієнти поглинання та дихроїзм молекул барвника, розчинених у матрищі ХРК. Велике значення $S=0,55$ для молекул барвника в матриці РК засвідчує, щзо иі молекули орієнтовані в площині, майже паралельній до нематичних молекул. Лазерне випромінювання від холестерика, легованого барвником з планарною орієнтацією, який володіє текстурою Гранджана, спостерігаємо на довгохвильовому краю забороненої фотонної зони (ЗФ3) холестерика. Це підтверджує характер лазерної генерації за механізмом ЗФЗ і додатково доводить, що молекули барвника паралельні до площчин молекул ХРК. Ми також виявили, щзо досліджений нами легований барвником ХРК - ие матеріал, перспективний для лазерної генерації в холестеричних матрииях 